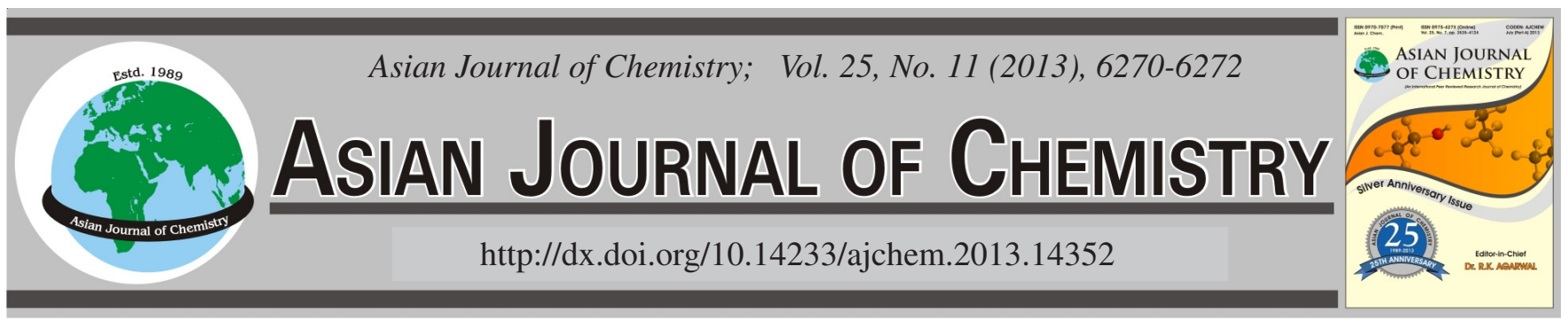

\title{
A Novel Three-Dimensional Chiral Cadmium-Tartrate Compound: Hydrothermal Synthesis and Crystal Structures
}

\author{
GuO-Dong Feng* and LuAn JiAng
}

Key Laboratory of Functional Coordination Compounds, Department of Chemistry and Chemical Engineering, Baoji University of Arts and Science, No. 1 Hi-Tech Avenue, Baoji 721013, Shaanxi Province, P.R. China

*Corresponding author: Tel: +86 917 3566589; E-mail: fengguodong00805@163.com

(Received: 20 July 2012;

Accepted: 6 May 2013)

AJC-13453

\begin{abstract}
One novel cadmium-tartrate compound exhibiting three-dimensional chiral structure, namely $\left\{\left[\mathrm{Cd}_{3}(\mathrm{TTA})_{3}\left(\mathrm{H}_{2} \mathrm{O}\right)\right]\left(\mathrm{H}_{2} \mathrm{O}\right)_{2}\right\}_{\mathrm{n}}(\mathbf{1})\left(\mathrm{H}_{2} \mathrm{TTA}=\right.$ tartaric acid), was obtained by the reactions of the cadmium salts with corresponding $\mathrm{H}_{2}$ TTA under hydrothermal conditions and characterized by X-ray single-crystal diffraction and elemental analysis. The crystal belongs to the orthorhombic system, space group $\mathrm{P} 22_{1} 2_{1} 2_{1}$ with a $=$ $0.63507(8) \mathrm{nm}, \mathrm{b}=1.7116(2) \mathrm{nm}, \mathrm{c}=1.8492(2) \mathrm{nm}, \alpha=\beta=\gamma=90^{\circ}, \mathrm{V}=2.0101(4) \mathrm{nm}^{3}, \mathrm{D}_{\mathrm{c}}=2.717 \mathrm{~g} \mathrm{~cm}^{-3}, \mathrm{Z}=4, \mathrm{~F}_{(000)}=1556, \mathrm{Goof}=$ $1.033, \mathrm{R}_{1}=0.0326, \mathrm{wR}_{2}=0.0703$. The compound 1 shows an interesting three-dimensional network with left helical chains. CCDC: 837585 .
\end{abstract}

Key Words: Cadmium(II) polymer, Crystal structure, Tartaric acid.

\section{INTRODUCTION}

Recently, chiral inorganic-organic materials have been quickly developing, not only because of their numerous potential applications in nonlinear optics, enantioselective catalysis and medicine, but also owing to their intriguing variety of architectures and topologies ${ }^{1}$. Hence, researches in this field have been concentrated on modifying the building blocks and controlling the assembled motifs for required products via selecting suitable chiral organic molecules and metal cations ${ }^{2,3}$. L(D)-Tartaric acid, a simple and inexpensive chiral ligand source, which has attracted many interests of chemistry for studying the self-assembly of MOFs because of their conformational flexibility and diversity in complexing behaviour, which may offer various possibilities for the synthesis of polymeric complexes containing transition metal cations with unique structures and useful properties ${ }^{4}$. Meanwhile, extensive work has been carried out by self-assembly reactions of carboxylate-containing ligands, such as trimesic acid(TMA) $)^{5,6}$. However, to the best of our knowledge, contrary to the fruitful production of hybrid materials assembled from chiral L(D)tartrate ligand, the chiral 3-D open-framework constructed from the ligand remains relatively rare ${ }^{7}$. Using transition metal ions as nodes in the construction of chiral polymeric frameworks is our currently synthetic strategy. Consequently, our research is focused on synthesizing novel functional 3-D chiral networks with interesting structural diversities, especially new topologies, based on transition metal-tartrate coordination complexes as linkers as chiral building units. In this paper, we report a novel novel 3-D open-framework of distinctive topologies, $\left\{\left[\mathrm{Cd}_{3}(\mathrm{TTA})_{3}\left(\mathrm{H}_{2} \mathrm{O}\right)\right]\left(\mathrm{H}_{2} \mathrm{O}\right)_{2}\right\}_{\mathrm{n}}$, predominated by the chiralities of the tartaric acid $\left(\mathrm{H}_{2} \mathrm{TTA}\right)$ under hydrothermal conditions, which may provide useful strategy to construct new coordination frameworks.

\section{EXPERIMENTAL}

All chemical reagents were of analytical grade and used without further purification. $\mathrm{C}, \mathrm{H}$ and $\mathrm{N}$ analyses were made on Elementar Vario EL-III elemental analyzer. The single-crystal structure of the compound $\mathbf{1}$ was determined on a Bruker APXII CCD diffractometer.

The compound $\mathbf{1}$ was prepared by the mixture of $\mathrm{Cd}\left(\mathrm{NO}_{3}\right)_{2} \cdot 4 \mathrm{H}_{2} \mathrm{O}(0.154 \mathrm{~g}, 0.5 \mathrm{mmol})$, L-tartaric acid $(0.0750$ $\mathrm{g}, 0.5 \mathrm{mmol})$ and $\mathrm{H}_{2} \mathrm{O}(16 \mathrm{~mL})$ was heated at $160^{\circ} \mathrm{C}$ for 3 days in a $25 \mathrm{~mL}$ Teflon-lined stainless steel vessel under autogenous pressure. After the reaction mixture was slowly cooled down to room temperature, colourless block crystals were obtained. Yield: $75 \%$. anal. calcd. (\%) for compound $1, \mathrm{C}_{12} \mathrm{H}_{5} \mathrm{O}_{21} \mathrm{Cd}_{3}$ : C, 17.51; H, 0.6. Found (\%): C, 18.75; H, 0.81 .

Structure determination: A colourless block single crystal of compound 1 with $0.32 \mathrm{~mm} \times 0.21 \mathrm{~mm} \times 0.11 \mathrm{~mm}$ was carefully selected under a polarizing microscope and were mounted on a glass fiber and used for X-ray diffraction analyses. Single crystal structure determination by X-ray diffraction 
measurements were performed using a Bruker APXII CCD diffractometer with graphite monochromated $\mathrm{MoK}_{\alpha}(\mathrm{k}=$ $0.71073 \AA)$ radiation in the range of $1.62 \leq \theta \leq 28.34^{\circ}(-8 \Leftarrow$ $\mathrm{h} \Leftarrow 8,-22 \Leftarrow \mathrm{k} \Leftarrow 21,-17 \Leftarrow 1 \Leftarrow 24)$ at $293 \mathrm{~K}$. Absorption corrections were applied using the multi-scan technique ${ }^{8}$. A total of 12178 reflections including 4733 unique ones were collected, of which 4733 with $\mathrm{I}>2 \sigma(\mathrm{I})$ were considered as observed and used in the succeeding refinements. The structure was solved by the Direct Method and refined by full-matrix least-square techniques on $\mathrm{F}^{2}$ using SHELXL-979. All of the non-hydrogen atoms were refined anisotropically ${ }^{10}$. The $\mathrm{H}$ atoms attached to $\mathrm{C}$ atoms were positioned geometrically, with Uiso values derived from Ueq values of the corresponding $\mathrm{C}$ atom. The final $\mathrm{R}=0.0326$ and $\mathrm{wR}=0.0703, \mathrm{~S}=1.033,(\Delta \rho)_{\max }$ $=0.978$ and $(\Delta \rho)_{\min }=-0.759 \mathrm{e} / \AA^{3}$.

Crystallographic data for the structural analysis(es) have been deposited with the Cambridge Crystallographic Data Centre, CCDC No.: 837585 for the compound $\mathbf{1}$.

\section{RESULTS AND DISCUSSION}

Crystal structure: The title compound was obtained by hydrothermal method. The crystallographic analysis revealed that the compound $\mathbf{1}$ crystallized in the chiral space group $\mathrm{P} 22_{1} 2_{1}$, which is quite similar with the reported cadmiumtartrate complex obtained by cooperative synthesis with sulfate $^{11}$. As shown in Fig. 1, the asymmetric unit of compound 1 contains three $\mathrm{Cd}(\mathrm{II})$ ions, three TTA ${ }^{2-}$ ligands, one coordinate water and two free water molecules. In compound $\mathbf{1}$, the crystallographically independent $\mathrm{Cd}$ centers have three different coordinated modes: $\mathrm{Cd}(1)$ site is six-coordinated with five carboxylic $\mathrm{O}$ atoms (Cd-O:2.238(4)-2.643(4)) from four distinct tartrate ligands and one hydroxyl $\mathrm{O}$ atom $(\mathrm{Cd}-$ $\mathrm{O}: 2.319(4)$ ), in which the bond angles $\mathrm{O}-\mathrm{Cd}-\mathrm{O}$ in the range 52.82(15)-178.12(15) $)^{\circ}$. While the $\mathrm{Cd}(3)$ ions are six-coordinated via four carboxylate oxygen atoms(Cd-O:2.195(4)-2.445(5)) from three tartrate ligands, one hydroxyl oxygen atom $(\mathrm{Cd}-$ $\mathrm{O}: 2.329(4))$ and one aqua ligands (Cd-O:2.329(5)), in which the bond angles $\mathrm{O}-\mathrm{Cd}-\mathrm{O}$ in the range 53.67(14)-173.77(18) ${ }^{\circ}$. Different from the $\mathrm{Cd}(1)$ and $\mathrm{Cd}(3)$, the $\mathrm{Cd}(2)$ site is eightcoordinated via four carboxylate with four carboxylic $\mathrm{O}$ atoms (Cd-O:2.262(4)-2.349(4)) and four hydroxyl O atoms(Cd-O: 2.428(4)- 2.594(4)) from four distinct tartrate ligands in which the bond angles O-Cd-O in the range 65.41(13)- 146.29(14) ${ }^{\circ}$. There are two kinds of TTA ${ }^{2-}$ ligands of different coordination modes (Fig. 2). One act as $\mu_{4}$-bridges linking three crystallographically independent $\mathrm{Cd}(\mathrm{II})$ atoms (e.g., the ligands containing $\mathrm{C} 1, \mathrm{C} 4, \mathrm{C} 5, \mathrm{C} 6)$, in which the hydroxyl $\mathrm{O}$ atoms are in chelating coordination mode with their neighboring carboxylic $\mathrm{O}$ atoms and the carboxylate groups of $\mathrm{TTA}^{2-}$ ligand are in $\mu_{2}-\eta^{1}: \eta^{1}$ mode connecting two metal atoms ${ }^{12,13}$ (Fig. 2a). The other TTA ${ }^{2-}$ ligands (e.g., the ligands containing $\mathrm{C} 2, \mathrm{C} 3, \mathrm{C} 11$, C12) serve as $\mu_{4}$-bridges linking two crystallographically independent $\mathrm{Cd}(\mathrm{II})$ atoms, in which the hydroxyl $\mathrm{O}$ atom from the $\mathrm{C} 2$ is in chelating coordination mode with their neighbouring carboxylic $O$ atoms and the carboxylate groups adopt $\mu_{2}-\eta^{1}: \eta^{1}$ mode connecting two metal atoms, meanwhile, in which the hydroxyl $\mathrm{O}$ atom from the $\mathrm{C} 11$ do not participate in the coordination and the carboxylate groups of $\mathrm{TTA}^{2-}$ are in monodentate

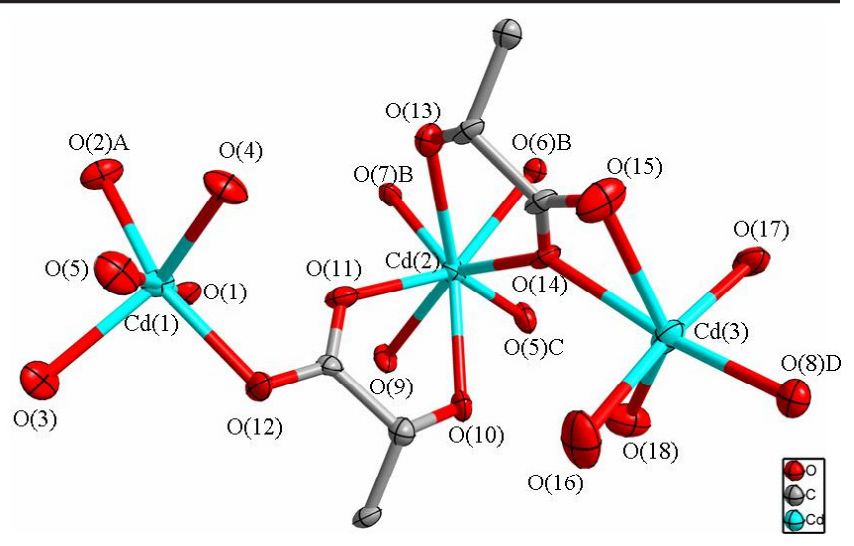

Fig. 1. Coordination environment of the $\mathrm{Cd}(\mathrm{II})$ atom in compound $\mathbf{1}$. The thermal ellipsoids are drawn at $50 \%$ probability and hydrogen atoms were omitted for clarity. Symmetry code: A: $x+1 / 2,-y-1 / 2,-z+1$; $\mathrm{B}: \mathrm{x}+1, \mathrm{y}, \mathrm{z} ; \mathrm{C}:-\mathrm{x}+3, \mathrm{y}+1 / 2,-\mathrm{z}+1 / 2 ; \mathrm{D}:-\mathrm{x}+5 / 2,-\mathrm{y}, \mathrm{z}-1 / 2$

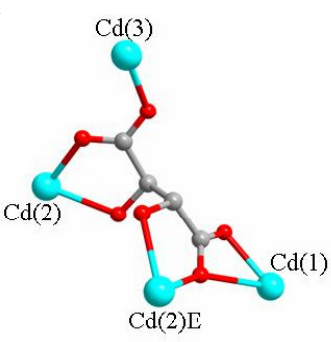

a

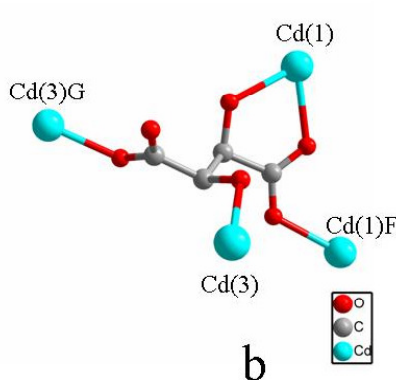

b
Fig. 2. Different coordination modes of TTA ${ }^{2-}$ ligands found in compound 1. Colour codes: colour codes: $\mathrm{Cd}$, teal; $\mathrm{N}$, blue; $\mathrm{C}$, gray; O, red; symmetry code: E: -1+x, y, z; F: -1/2+x, -1/2-y, 1-z; G:2-x, -1/2+y, $1 / 2-\mathrm{z}$

mode (Fig. 2b). Owning to the special coordination modes, the TTA ${ }^{2-}$ ligand acts as four-connecting spots to connect the $\mathrm{Cd}$ centers to lead to the formation of an interesting threedimensional network with left helical chains ${ }^{14}$ (Fig. 3). Moreover, the hydrogen bonding interactions between coordinated water molecules and $\mathrm{O}$ atoms of free water molecules play important roles in stabilizing the whole 3D supramolecular structure. Selected bond distances and bond angles are shown in Table-1. The hydrogen binding of compound $\mathbf{1}$ is detailed in Table-2.

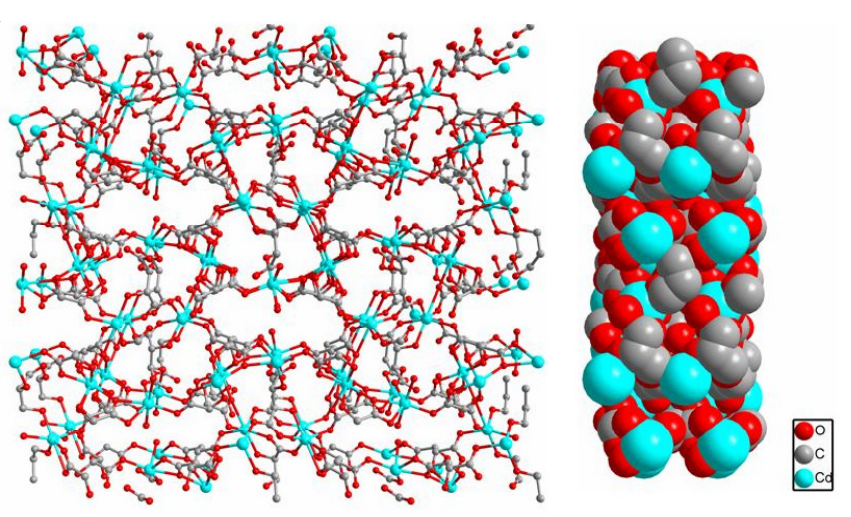

Fig. 3. (a) Crystal packing of compound $\mathbf{1}$ along the a axis. (b) Spacefilling model of the three-dimensional network along the $\mathrm{c}$ axis. Colour codes: colour codes: Cd, teal; N, blue; C, gray; O, red; (for interpretation of the references in colour in this figure legend, the reader is referred to the web version of this article) 
TABLE-1

SELECTED BOND LENGTHS (nm) AND BOND ANGLES $\left({ }^{\circ}\right)$

\begin{tabular}{|c|c|c|c|}
\hline Bond & Dist. & Bond & Dist. \\
\hline $\mathrm{O}(12)-\mathrm{Cd}(1)$ & $0.2238(4)$ & $\mathrm{O}(13)-\mathrm{Cd}(2)$ & $0.2594(4)$ \\
\hline $\mathrm{O}(1)-\mathrm{Cd}(1)$ & $0.2319(4)$ & $\mathrm{O}(10)-\mathrm{Cd}(2)$ & $0.2428(4)$ \\
\hline $\mathrm{O}(4)-\mathrm{Cd}(1)$ & $0.2274(4)$ & $\mathrm{O}(11)-\mathrm{Cd}(2)$ & $0.2262(4)$ \\
\hline $\mathrm{O}(5)-\mathrm{Cd}(1)$ & $0.2643(4)$ & $\mathrm{Cd}(2)-\mathrm{O}(6) \mathrm{B}$ & $0.2455(4)$ \\
\hline $\mathrm{Cd}(1)-\mathrm{O}(3)$ & $0.2265(4)$ & $\mathrm{O}(14)-\mathrm{Cd}(2)$ & $0.2349(4)$ \\
\hline $\mathrm{Cd}(1)-\mathrm{O}(2) \mathrm{A}$ & $0.2272(4)$ & $\mathrm{Cd}(2)-\mathrm{O}(7) \mathrm{B}$ & $0.2283(4)$ \\
\hline $\mathrm{O}(16)-\mathrm{Cd}(3)$ & $0.2329(5)$ & $\mathrm{Cd}(2)-\mathrm{O}(5) \mathrm{C}$ & $0.2305(4)$ \\
\hline $\mathrm{O}(17)-\mathrm{Cd}(3)$ & $0.2329(4)$ & $\mathrm{Cd}(2)-\mathrm{O}(9)$ & $0.2556(4)$ \\
\hline $\mathrm{O}(15)-\mathrm{Cd}(3)$ & $0.2445(5)$ & $\mathrm{O}(18)-\mathrm{Cd}(3)$ & $0.2220(5)$ \\
\hline $\mathrm{O}(14)-\mathrm{Cd}(3)$ & $0.2375(4)$ & $\mathrm{Cd}(3)-\mathrm{O}(8) \mathrm{D}$ & $0.2195(4)$ \\
\hline Bond & Dist. & Bond & Dist. \\
\hline $\mathrm{C}(11)-\mathrm{O}(17)-\mathrm{Cd}(3)$ & $119.0(3)$ & $\mathrm{C}(10)-\mathrm{O}(15)-\mathrm{Cd}(3)$ & $91.6(4)$ \\
\hline $\mathrm{C}(12)-\mathrm{O}(18)-\mathrm{Cd}(3)$ & $120.3(4)$ & $\mathrm{C}(9)-\mathrm{O}(13)-\mathrm{Cd}(2)$ & $115.5(3)$ \\
\hline $\mathrm{O}(16)-\mathrm{Cd}(3)-\mathrm{O}(14)$ & $95.46(16)$ & $\mathrm{C}(4)-\mathrm{O}(7)-\mathrm{Cd}(2) \mathrm{E}$ & $120.5(4)$ \\
\hline $\mathrm{C}(4)-\mathrm{O}(8)-\mathrm{Cd}(3) \mathrm{D}$ & $123.9(4)$ & $\mathrm{C}(8)-\mathrm{O}(11)-\mathrm{Cd}(2)$ & $122.9(4)$ \\
\hline $\mathrm{C}(8)-\mathrm{O}(12)-\mathrm{Cd}(1)$ & $113.3(4)$ & $\mathrm{C}(5)-\mathrm{O}(6)-\mathrm{Cd}(2) \mathrm{E}$ & $114.1(3)$ \\
\hline $\mathrm{O}(3)-\mathrm{Cd}(1)-\mathrm{O}(5)$ & $77.34(14)$ & $\mathrm{O}(12)-\mathrm{Cd}(1)-\mathrm{O}(5)$ & $88.73(15)$ \\
\hline $\mathrm{Cd}(2)-\mathrm{O}(14)-\mathrm{Cd}(3)$ & $138.79(18)$ & $\mathrm{O}(11)-\mathrm{Cd}(2)-\mathrm{O}(7) \mathrm{B}$ & $92.36(14)$ \\
\hline $\mathrm{O}(11)-\mathrm{Cd}(2)-\mathrm{O}(5) \mathrm{C}$ & $142.95(15)$ & $\mathrm{O}(7) \mathrm{B}-\mathrm{Cd}(2)-\mathrm{O}(5) \mathrm{C}$ & $96.05(15)$ \\
\hline $\mathrm{O}(11)-\mathrm{Cd}(2)-\mathrm{O}(14)$ & $94.05(15)$ & $\mathrm{O}(7) \mathrm{B}-\mathrm{Cd}(2)-\mathrm{O}(14)$ & $135.60(15)$ \\
\hline $\mathrm{O}(5) \mathrm{C}-\mathrm{Cd}(2)-\mathrm{O}(14)$ & $104.50(14)$ & $\mathrm{O}(11)-\mathrm{Cd}(2)-\mathrm{O}(10)$ & $69.37(14)$ \\
\hline $\mathrm{O}(7) \mathrm{B}-\mathrm{Cd}(2)-\mathrm{O}(10)$ & $146.00(15)$ & $\mathrm{O}(5) \mathrm{C}-\mathrm{Cd}(2)-\mathrm{O}(10)$ & $84.19(15)$ \\
\hline $\mathrm{O}(18)-\mathrm{Cd}(3)-\mathrm{O}(14)$ & $82.71(16)$ & $\mathrm{O}(11)-\mathrm{Cd}(2)-\mathrm{O}(6) \mathrm{B}$ & $142.56(14)$ \\
\hline $\mathrm{O}(7) \mathrm{B}-\mathrm{Cd}(2)-\mathrm{O}(6) \mathrm{B}$ & $69.41(13)$ & $\mathrm{O}(5) \mathrm{C}-\mathrm{Cd}(2)-\mathrm{O}(6) \mathrm{B}$ & $73.37(14)$ \\
\hline $\mathrm{O}(14)-\mathrm{Cd}(2)-\mathrm{O}(6) \mathrm{B}$ & 79.33(13) & $\mathrm{O}(10)-\mathrm{Cd}(2)-\mathrm{O}(6) \mathrm{B}$ & $141.06(13)$ \\
\hline
\end{tabular}

TABLE-2

HYDROGEN BOND LENGTHS (nm) AND BOND ANGLES $\left(^{\circ}\right)$ FOR COMPOUND 1

\begin{tabular}{lcccc}
\hline \multicolumn{1}{c}{$\mathrm{D}-\mathrm{H}$} & $\mathrm{d}(\mathrm{D}-\mathrm{H})$ & $\mathrm{d}(\mathrm{H} \cdots \mathrm{A})$ & $<\mathrm{DHA}$ & $\mathrm{d}(\mathrm{D} \cdots \mathrm{A})$ \\
\hline $\mathrm{O}(1 \mathrm{~W})-\mathrm{H}(111) \cdots \mathrm{O}(2)$ & 0.77 & 2.45 & 133 & $3.039(7)$ \\
$\mathrm{O}(1 \mathrm{~W})-\mathrm{H}(111) \cdots \mathrm{O}(17)$ & 0.77 & 2.44 & $131^{\prime}$ & $3.000(7)$ \\
$\mathrm{O}(2 \mathrm{~W})-\mathrm{H}(222) \cdots \mathrm{O}(19) \mathrm{H}$ & 0.85 & 2.35 & 130 & $2.97(3)$ \\
\hline
\end{tabular}

Symmetry code: $\mathrm{H}: 1-\mathrm{x},-1 / 2+\mathrm{y}, 1 / 2-\mathrm{z}$.

\section{Conclusion}

In summary, a new chiral cadmium-tartrate compound was synthesized from tartaric acid ligand, which has been performed in the hydrothermal reaction condition and determined its structure $\left.\left\{\mathrm{Cd}_{3}(\mathrm{TTA})_{3}\left(\mathrm{H}_{2} \mathrm{O}\right)\right]\left(\mathrm{H}_{2} \mathrm{O}\right)_{2}\right\}_{\mathrm{n}}\left(\mathrm{C}_{12} \mathrm{H}_{5} \mathrm{Cd}_{3} \mathrm{O}_{21}\right.$, $\mathrm{Mr}=822.36$ ) using single-crystal $\mathrm{X}$-ray diffraction analysis, the successful syntheses of the compounds indicate that the tartaric acid ligand is a flexibility and multifunctional ligand potentially able to offer various possibilities for construction of frameworks with unique structures and useful properties.

\section{ACKNOWLEDGEMENTS}

This work was financially supported by the Research Grant of Phytochemistry Key Laboratory of Shaanxi Province (No. 11JS006,11JS007) and the Scientific Research Fund of Shaanxi Provincial Education Department (No. 11JK0603).

\section{REFERENCES}

1. O.M. Yaghi, M. O'Keeffe, N.W. Ockwig, H.K. Chae, M. Eddaoudi and J. Kim, Nature, 423, 705 (2003).

2. P. Kanoo, K.L. Gurunatha and T.K. Maji, Cryst. Growth Design, 9, 4147 (2009).

3. W.H. Wang, P.H. Xi, X.Y. Su, J.B. Lan, Z.H. Mao, J.S. You and R.G. Xie, Cryst. Growth Design, 7, 741 (2007).

4. Y.J. Kim, M. Suh and D.Y. Jung, Inorg. Chem., 43, 245 (2004).

5. N.L. Rosi, M. Eddaoudi, J. Kim, M. O'Keeffe and O.M. Yaghi, Angew. Chem. Int. Ed., 41, 284 (2002).

6. C. Serre, F. Millange, C. Thouvenot, N. Gardant, F. Pelle and G. Ferey, J. Mater. Chem., 14, 1540 (2004).

7. S. Thushari, J.A.K. Cha, H.H.Y. Sung, S.S.Y. Chui, A.L.F. Leung, Y.F. Yen and I.D. Williams, Chem. Commun., 44, 5515 (2005).

8. T. Higashi, Program for Absorption Correction, Rigaku Corporation, Tokyo, Japan (1995).

9. SHELXTL, Version 5.1, Siemens Industrial Automation, Inc. (1997).

10. G.M. Sheldrick, SHELXL-97, Program for the Refinement of Crystal Structure, University of Göttingen, Germany (1997).

11. H.X. Guo, Q.Y. Liu, L. Yang and W. Weng, Inorg. Chem. Commun., 11, 859 (2008).

12. H.G.Yao, M. Ji, S.H. Ji, Y.S. Jiang, L. Li and Y.L. An, Inorg. Chem. Commun., 10, 440 (2007).

13. Y. Wang, G.X. Liu and Y.C. Chen, Chin. J. Inorg. Chem., 28, 1084 (2009).

14. Y. Wang, G. Liu, Y. Chen and K. Wang, Inorg. Chim. Acta, 363, 2668 (2010). 